\title{
Histochemistry of the neuroglia and myelin in experimental cerebral oedema
}

\author{
M. Z. M. IBRAHIM, R. S. MORGAN, AND C. W. M. ADAMS \\ From the Department of Pathology, Guy's Hospital Medical School, London
}

Several different forms of experimental cerebral oedema have been produced and studied by histological, histochemical, or electron-microscopic means. Such oedema has been produced by injury (Klatzo, Piraux, and Laskowski, 1958; Torack, Terry, and Zimmerman, 1959; Rubinstein, Klatzo, and Miquel, 1962), overhydration (Gerschenfeld, Wald, Zadunaisky, and De Robertis, 1959; Luse, 1960; Luse and Harris, 1961; Hills and Spector, 1963), triethyl-tin intoxication (Magee, Stoner, and Barnes, 1957; Torack, Terry, and Zimmerman, 1960; Aleu, Katzman, and Terry, 1963; Kalsbeck and Cumings, 1963), and by immunological vascular damage (Leibowitz, Morgan, Berkinshaw-Smith, and Payling Wright, 1961).

It has often been suggested that cerebral oedema may play a part in the demyelinating processes of both primary demyelinating conditions and Wallerian or tract degeneration (for example, see Greenfield, 1939; Barlow, 1956). Likewise a marked increase in the water content of the degenerating nerve is seen soon after its section (Johnson, McNabb, and Rossiter, 1950), and the myelin sheath is known to be extremely unstable when exposed to water and buffer solutions in vitro (see Adams, Davison, and Gregson, 1963).

In previous communications in this Journal we have described a characteristic neuroglial reaction that accompanies or precedes demyelination in multiple sclerosis and experimental cyanide encephalopathy, namely, oligodendroglial hyperplasia, hypertrophy, and enzymic hyperactivity (Ibrahim and Adams, 1963; Ibrahim, Briscoe, Bayliss, and Adams, 1963). The purpose of this present paper is to determine whether similar oligodendroglial and myelin changes occur in experimentally-produced cerebral oedema.

\section{METHOD}

VASOPRESSIN-INDUCED 'OEDEMA' The method followed was that devised by Hills and Spector (1963) modified

${ }^{1}$ Partly supported by grants from the Multiple Sclerosis Society and the National Fund for Research into Poliomyelitis and Other Crippling
Diseases. from Gerschenfeld et al. (1959). Each rat was injected with $0.05 \mathrm{ml}$. vasopressin (=1 B.P. unit) while under light ether anaesthesia; $10 \mathrm{~min}$. later each animal was reanaesthetized and injected intraperitoneally with sterile distilled water. Two rats were injected with $80 \mathrm{ml}$. water $/ \mathbf{k g}$. bodyweight over $24 \mathrm{hr}$., while seven other animals were given $50 \mathrm{ml}$. water $/ \mathrm{kg}$. bodyweight twice every day for one to three weeks. Two animals received dummy injections.

Animals were usually killed with chloroform and their brains were rapidly removed. A mid-coronal block of one hemisphere was then frozen onto a cryostat chuck next to the contralateral cerebral hemisphere from a control rat. This preparation was used for histochemical enzymic studies. Part of the other hemisphere from the experimental animal was fixed in $10 \%$ formol-5\% ammonium bromide for silver impregnation methods. Half of a hemisphere from each experimental animal and corresponding tissue from a control animal were weighed fresh, dried to constant weight at $110^{\circ} \mathrm{C}$., and then re-weighed.

TIN-INDUCED OEDEMA Six adult male albino rats of average weight $300 \mathrm{~g}$. were fed on stock rat cubes, which had been steeped in a solution of triethyl-tin hydroxide in arachis oil to give a final concentration of 20 p.p.m. These animals and corresponding controls were killed by decapitation between the seventh and 32nd days of the experiment. Their brains were removed and prepared in the way described above.

Cytological methods The same methods were employed for both experiments. Sections were stained by haematoxylin and eosin and by metal impregnation methods for oligodendrocytes, astrocytes, microglia, and neurones (for technical details see Ibrahim and Adams, 1963).

Histochemical methods The following histoenzymic methods were used:-lactic, succinic, glutamic, $\alpha$ glycerophosphate (NAD-linked), isocitric (NAD- and NADP-linked), malic and glucose-6-phosphate dehydrogenases; $\mathrm{NADH}_{2^{-}}$and $\mathrm{NADPH}_{2^{-}}$tetrazolium reductases; acid and alkaline phosphatases and uncharacterized $\mathrm{Ca}^{++}, \mathrm{Na}^{+}$-activated 'adenosine triphosphatase'. The technical procedures used for these enzymes were slight modifications of the conventional methods (for details see Adams, Davison, and Gregson, 1963). Some sections were also stained for cytochrome oxidase by Burstone's (1961) method, slightly modified by Barlow (1964, personal communication). Lipids were stained by the osmium tetroxide- $\alpha$-naphthylamine (OTAN) method 
(Adams, 1959) and by Sudan black. Preparations with the latter stain were viewed in polarized light (Diezel, 1957).

\section{RESULTS}

VASOPRESSIN-INDUCED , 'OEDEMA' None of the animals injected with vasopressin and water for two to three weeks showed a significant increase in cerebral water content, but three out of the five animals injected for one to seven days developed a moderate degree of cerebral 'oedema'. In these three animals the increase in cerebral water content varied between 0.91 and $1.2 \%$.

Minimal swelling of astrocytic perikarya and processes was observed in silver preparations in two out of the three animals with increased cerebral water content; but these changes were also seen in two out of the four animals injected for two to three weeks that had a normal cerebral water content, and in one out of two animals exposed to dummy injections. No morphological changes were seen in the myelin, oligodendroglia, microglia, and vessels in any of these animals. Likewise, no convincing enzymic changes were noted in either the neuroglia or vascular endothelium.

TIN-INDUCED OEDEMA The brains of all animals on the tin diet, with the exception of $\mathrm{T} 2$ killed at 10 days, were visibly swollen on naked-eye examination. Considerable grooving of the cerebral surfaces was observed around the superficial vessels. Two brains (T3 and T5) collapsed on cutting owing to extreme dilatation of the third and lateral ventricles. The overlying cortical grey matter, corpus callosum, and callosal radiations were slightly thinned and distorted. These changes were attributed to internal hydrocephalus as a result of obstruction to the lower part of the aqueduct of Sylvius; this blockage was probably due to pressure on the aqueduct exerted by the swollen white matter in the pons.

The water content of all brains was raised, except that of T2 (see Table I). (In this connexion, Hills and Spector (1963) found a mean water content in the normal rat brain of $78.4 \% \pm 0.4$.) The increase

TABLE I

WATER CONTENT OF THE BRAINS OF TIN-INTOXICATED AND CONTROL ANIMALS

\begin{tabular}{rlcc}
\multicolumn{2}{c}{ Exposure to Tin (days) } & \multicolumn{2}{c}{ Water Content (\%) } \\
\cline { 3 - 4 } & & Tin-intoxicated & Control \\
\hline 7 & (T1) & 81.01 & $78 \cdot 18$ \\
10 & (T2) & 78.00 & 78.04 \\
14 & (T3) & 82.30 & 80.60 \\
17 & (T4) & 79.93 & 77.78 \\
29 & (T5) & 80.68 & 77.54 \\
32 & (T6) & 80.13 & 79.61
\end{tabular}

in cerebral water content did not appear to be proportional to the duration of exposure to tin.

Myelin changes Vacuolation of the myelin was prominent from the seventh day of the experiment onwards. Such vacuoles first appeared in that region of the white matter of the corpus callosum and its radiations which borders on the grey cortical laminae. As the experiment progressed the amount of vacuolation and the area of involved white matter increased. By the 32nd day of exposure to tin all well-defined areas of white matter were severely involved, such as the corpus callosum, callosal radiations, white matter islands of the corpus striatum, internal capsule, cerebral peduncles, fimbriae, anterior and posterior commissures, optic tract, layers of white matter in the hippocampus, all tracts in the brainstem, pyramidal tracts and cerebellar white matter. The bordering zones of grey matter were also affected, such as the fifth and sixth cortical laminae and central nuclei of the cerebellum. These changes are illustrated in Figure 1. Even by the end of the experiment, the myelin appeared to be normal in between swollen and vacuolated areas, both in its structure and histochemical reactions. Thus, the preparations stained with Sudan black and OTAN (Fig. 2) showed no breakdown products (cholestero̊ esters) indicative of myelin destruction, as are see in Wallerian degeneration.

General histoenzymic reactions An early general ized loss of A.T.P.ase activity was seen in the braing of tin-intoxicated animals, but this decline in enzymie. activity could not be localized to any particular cel or component with the light microscope. At this early stage no generalized fall was detected in the activity of any dehydrogenase or nucleotide-tetrazolium reductase. However, after four weeks' exposure to

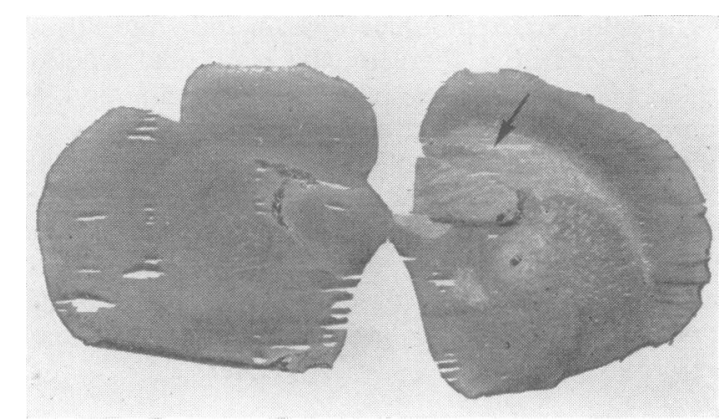

FIG. 1. Normal rat cerebral hemisphere on left; hemisphere on right from animal intoxicated with triethyl-tin $\mathrm{N}$ for 32 days. Note marked swelling and pallor of corpus callosum (arrow), callosal radiation, hippocampal commissure, and myelinated tracts of corpus callosum. Cryostat $\omega$ section, haematoxylin and eosin $\times 10$. 


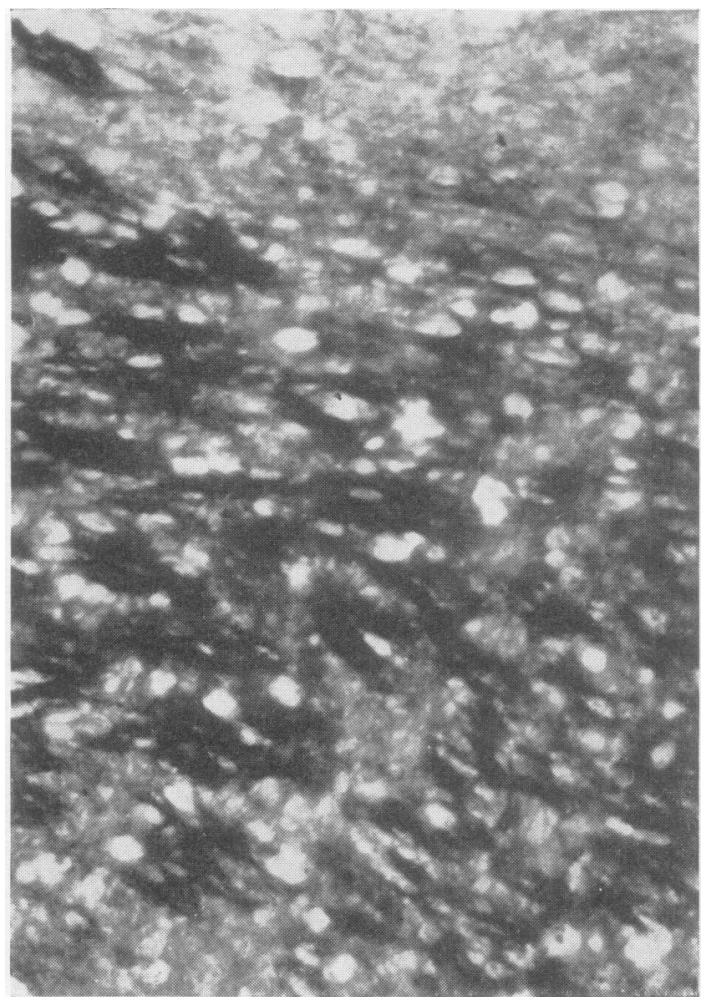

FIG. 2. Oedematous white matter in corpus callosum of rat intoxicated with triethyl-tin for 32 days. The myelin stains normally and no Marchi-positive breakdown products are seen. Osmium tetroxide-a naphthylamine (OTAN) $\times 94$.

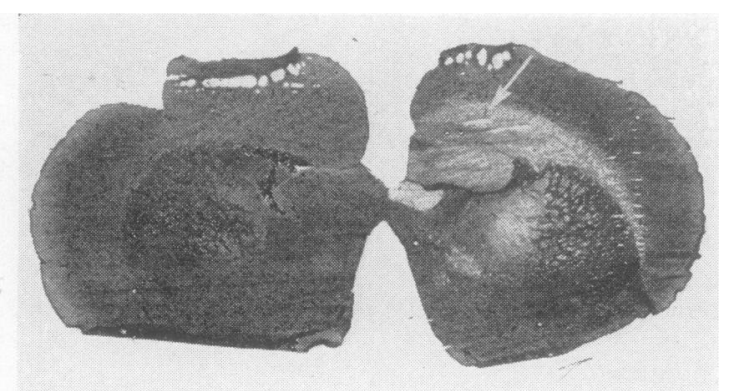

Fig. 3. As for Fig. 1 but stained by the PadykulaHerman method for A.T.P.ase. Note loss of enzyme activity from swollen white matter (arrow) in cerebral hemisphere from the tin-intoxicated rat (right).

tin, a marked generalized decline in the activity of all dehydrogenases studied as well as A.T.P.ase (Fig. 3) was noted in oedematous areas of the brain. This fall appeared to be partly due to the dilution of tissue components with oedema fluid, but it may also have been partly due to the impairment of cellular enzymic activity in the middle of such regions (see below).

Neuroglial changes No morphological or histoenzymic changes were seen in the astrocytes, oligodendroglia, and microglia in the brain during the first three weeks' exposure to tin (animals T1 to T4). Thereafter, astrocytes at the edge of oedematous areas (animals T5 and T6) showed moderate swelling of their processes and perikarya (Figs. 4 and 5). These changes were not of sufficient magnitude to enable these cells to be termed reactive astrocytes or gemistocytes, nor was there that degree of increased dehydrogenase activity in these cells which is usually seen in reactive astrocytes. Abundant swollen astroglial fibres were seen at the centre of oedematous areas and their perikarya, although scanty, were also swollen. Astrocytes in unaffected grey matter showed no morphological or enzymic changes.

Oligodendroglia at the edge of oedematous areas in animals T5 and T6 appeared to be both morphologically and enzymically normal (Figs. 6 and 7) but, in the centre of these areas, these cells showed reduced activity of lactic, iso-citric and glucose-6phosphate (Fig. 8) dehydrogenases, and of $\mathrm{NADH}_{2}-$ and $\mathrm{NADPH}_{2}$-tetrazolium reductases. Likewise, these cells showed some nuclear pallor at the centre of oedematous areas in preparations stained with haematoxylin and eosin.

Neuronal perikarya and processes Even in severely involved areas of grey matter neuronal perikarya and dendrites were little affected. The axons were frequently distorted by fluid accumulations in the white matter but they usually stained normally in Bielschowsky preparations. However, in a few of the most severe areas of oedema some fragmented axons were seen (Fig. 9). Blood vessels and the choroid plexus appeared normal, both in their morphology and dehydrogenase activities. The A.T.P.ase and alkaline phosphatase activities were slightly-but not strikingly -increased in the vascular wall and endothelium in the unaffected grey matter of the two animals (T5 and T6) that were exposed to tin for more than four weeks. These vascular phosphatases showed diminished activity at the centre of oedematous areas of these animals.

\section{DISCUSSION}

VASOPRESSIN-INDUCED 'OEDEMA' In our animals injected with distilled water and vasopressin, a moderate increase in cerebral water content was noted in three out of nine animals. No morphological or histoenzymic changes were noted in the 


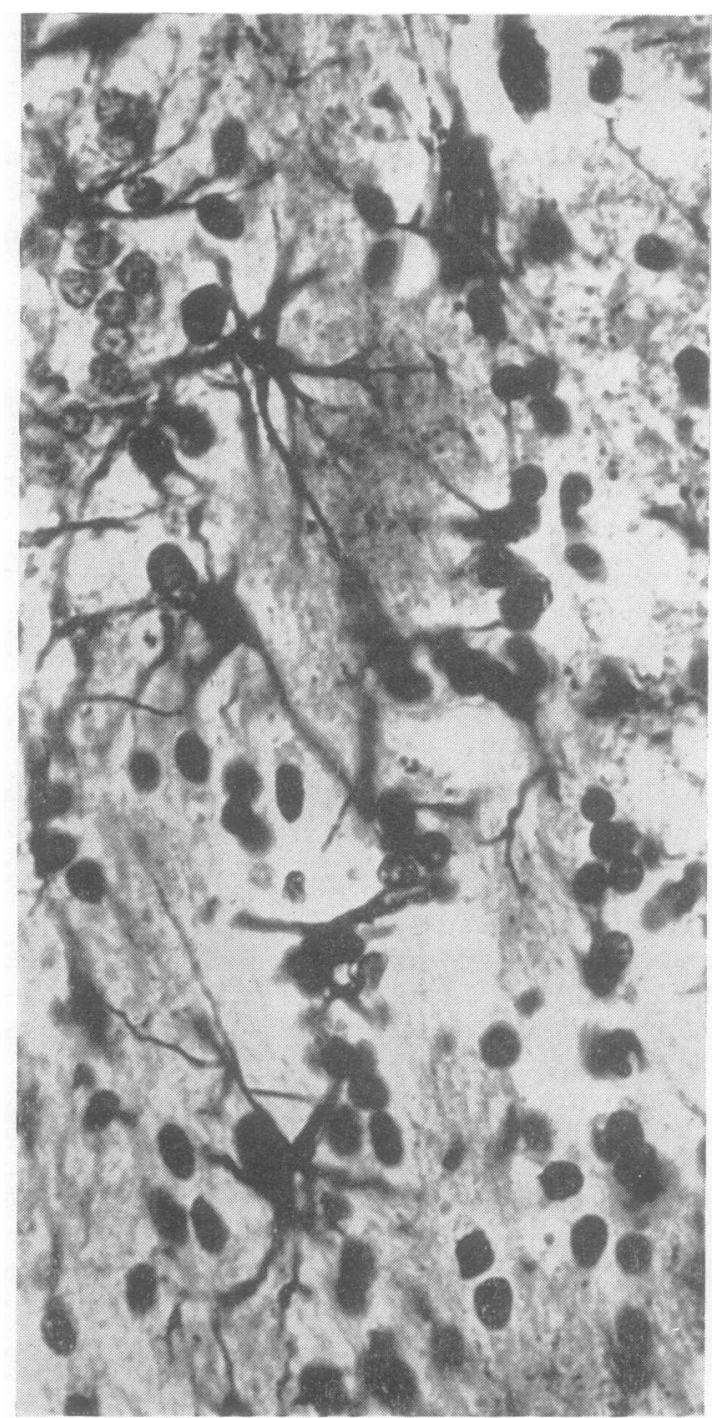

FIG. 4.

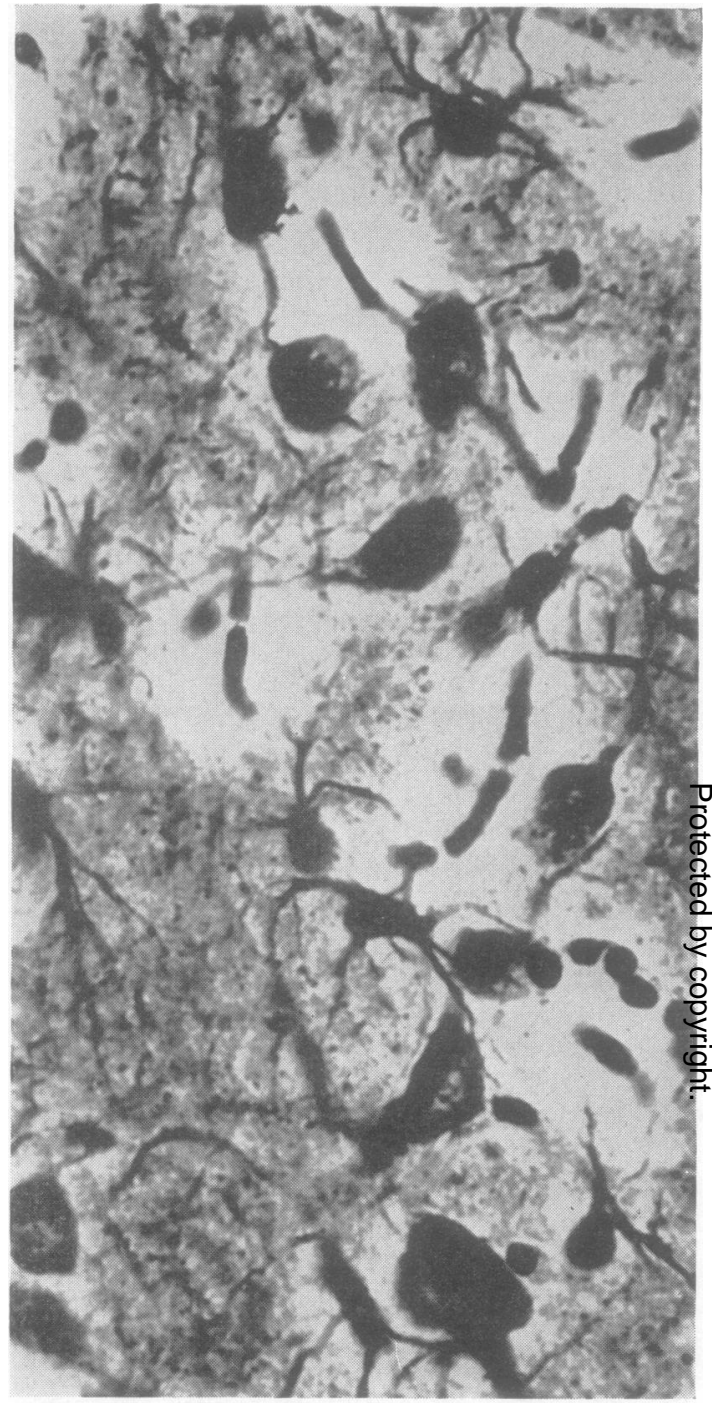

FIG. 5.

FIG. 4. Moderate swelling of astrocytic perikarya and processes in oedematous white matter of tin-intoxicated rat. Cajal-Bielschowsky silver method, $\times 940$.

FIG. 5. As for Fig. 4 in grey matter adjacent to oedematous white matter.

oligodendroglia and microglia in these three animals. Slight rather equivocal swelling was observed in the astrocytes of some injected animals, but this change could not be related to increased water content of the brain. Moreover, no enzymic changes were found in the astrocytes. This last observation contrasts with reports that these cells display markedly increased oxidative activity in subacute cerebral oedema (Schiffer and Vesco, 1963), in experimental traumatic oedema (Rubinstein et al., 1962), and on exposure to a high concentration of sodium ions in tissue culture (Friede, 1964). It could be argued, however, that our animals developed only minimal cerebral oedema. Their cerebral water content was substan- of tially less than that reported by Hills and Spector (1963), but was more than the trivial (or absent) increases recorded by Gerschenfeld et al. (1959). Nevertheless, Hills and Spector commented on the 

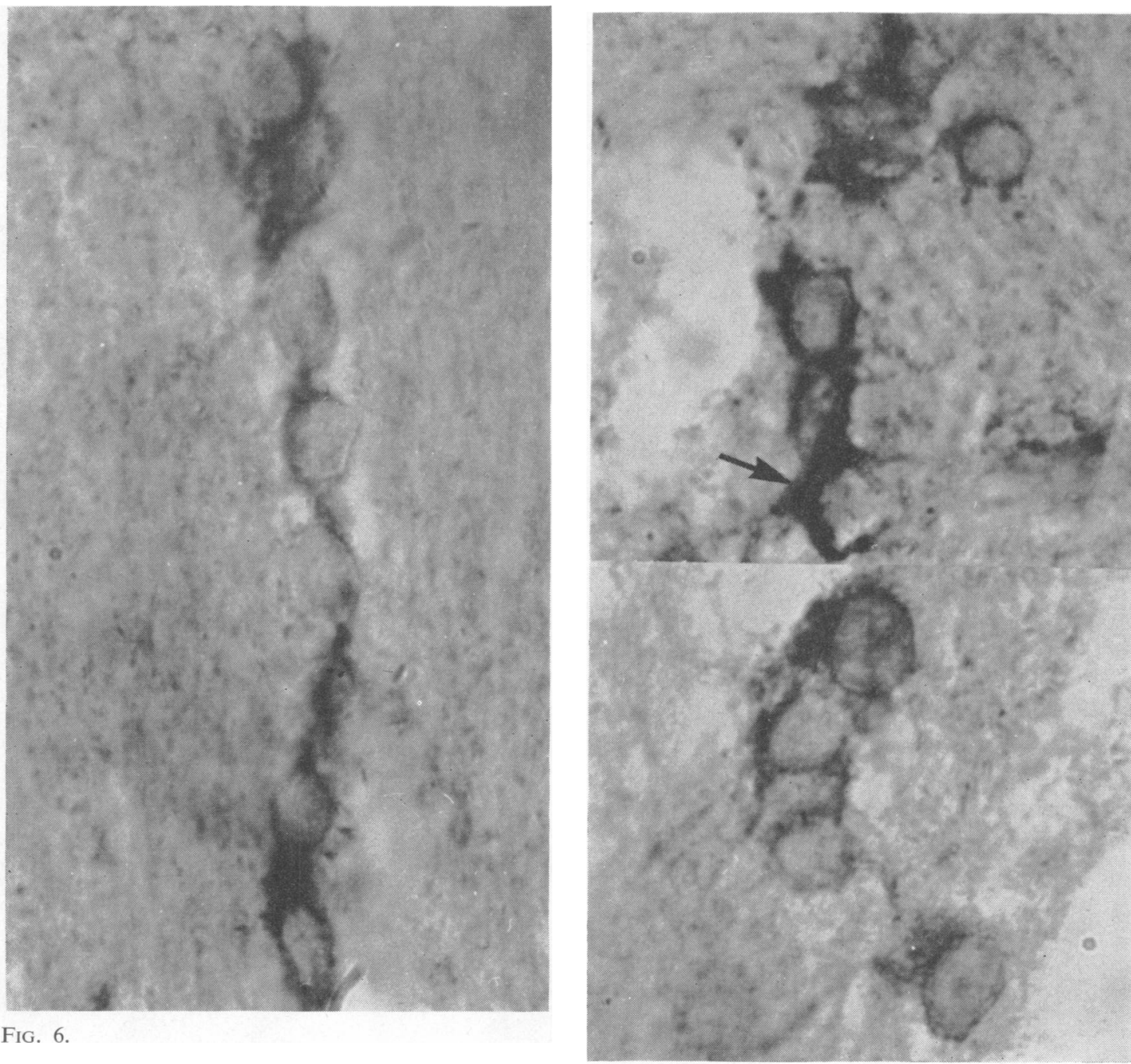

FIG. 7.

FIG. 6. Glucose-6-phosphate (NADP-linked) dehydrogenase activity in interfascicular oligodendroglia of corpus callosum of normal rat. Nitro-blue tetrazolium, $\times 2360$.

FIG. 7. Two representative fields from edge of oedematous area in corpus callosum in tin-intoxicated rat to show normal dehydrogenase activity in interfascicular oligodendroglia (c.f. Fig. 6). One cell (arrow) is probably a slightly activated astrocyte. Same method and magnification as Figure 6.

absence of neuroglial reaction in their more oedematous material.

TIN-INDUCED OEDEMA The cerebral oedema in triethyl-tin intoxication is localized to white matter and the adjacent grey matter. This oedema appears to be in or around the myelin sheaths and is not primarily within neuroglial cells, although in the later stages of the intoxication astrocytic perikarya and processes become moderately swollen. These observations are consistent with those of Aleu et al. (1963) and of Kalsbeck and Cumings (1963), who both showed that such oedema is mainly located in the myelin sheath. However, it could not be determined from our studies whether the oedema is interstitial (see Magee et al., 1957) or in myelin, but it was clear that the astrocytes are not principally involved (see Torack et al., 1960). 


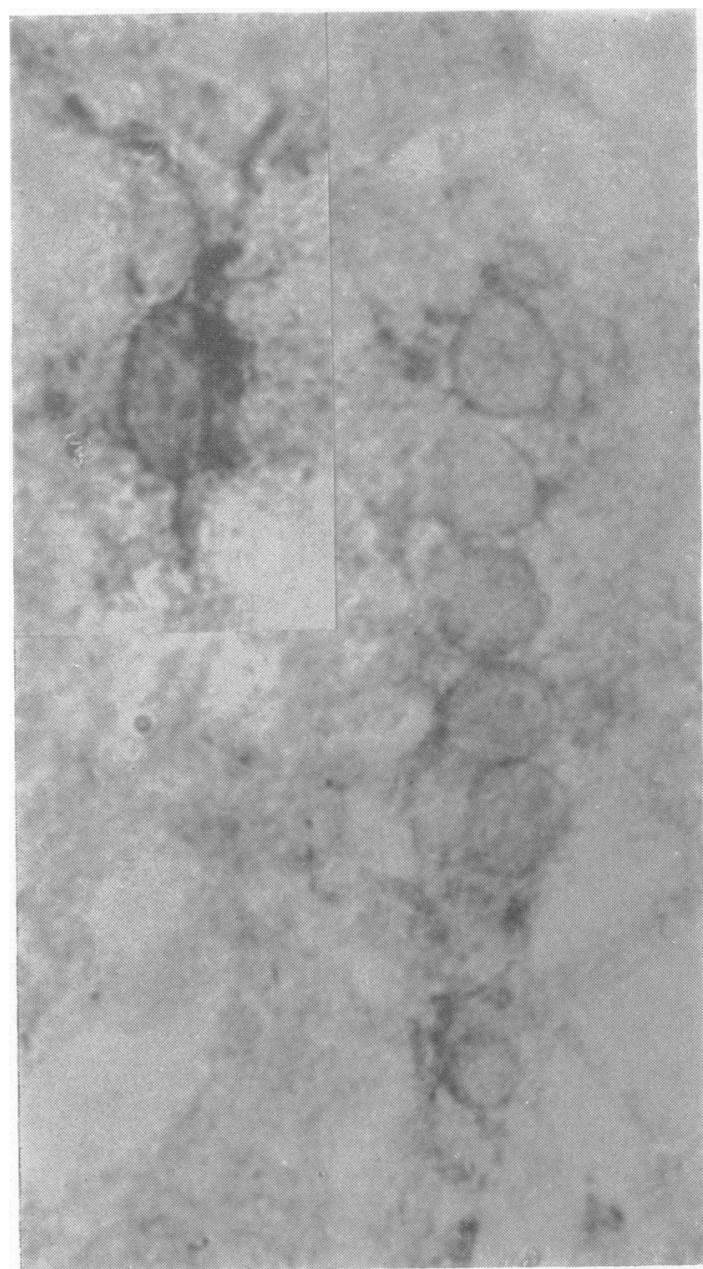

FIG. 8.

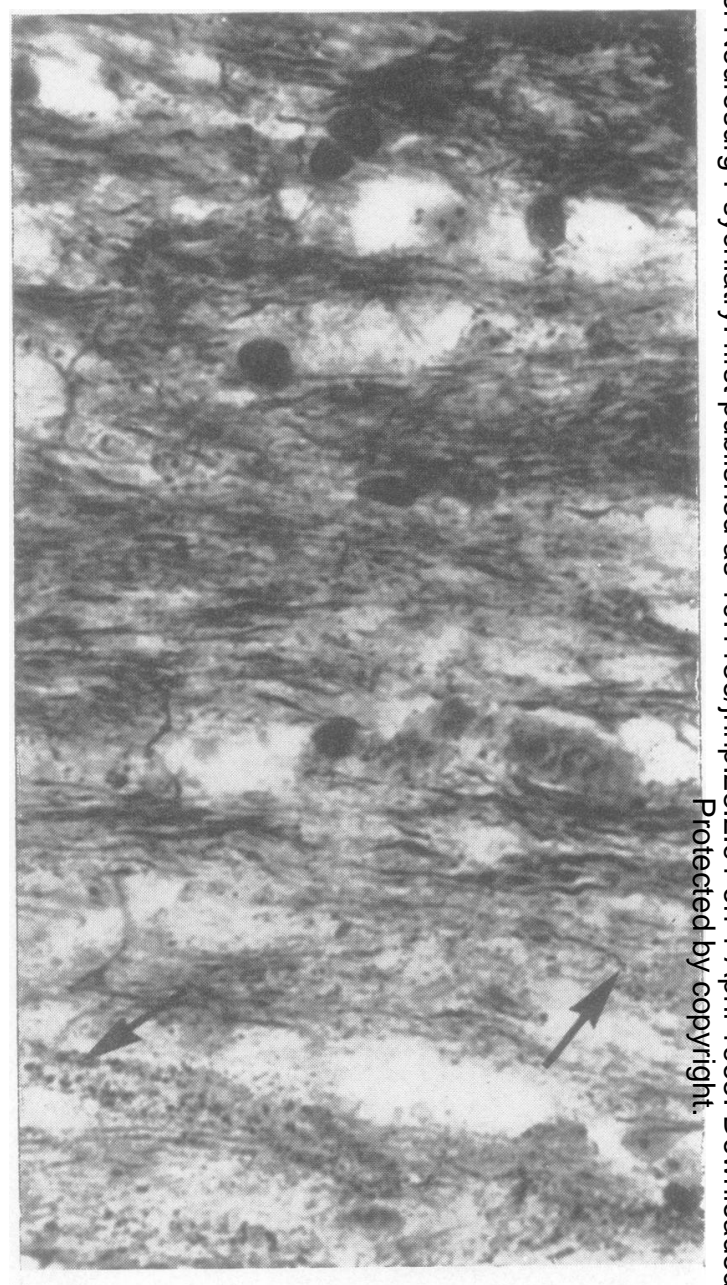

FIG. 9.

FIG. 8. Diminished dehydrogenase activity in interfascicular oligodendroglia at centre of same oedematous area as illustrated in Figure 7. Inset shows moderate activity in an astrocyte in this central area. Same method and magnification as Figure 6.

FIG. 9. Focal fragmentation of axons (arrows) in most severely oedematous area of corpus callosum in rat intoxicated with tin for 32 days. Bielschowsky silver method, $\times 940$.

The A.T.P.ase activity is inhibited by triethyl-tin (Aldridge, 1958), but the site of this inhibition in the brain cannot be localized to cells with the light microscope (Torack, 1965). The latter investigator, however, has shown by electron-histochemical means that this loss of A.T.P.ase activity is mainly from sites on astroglial plasma membranes. Oxidative enzyme activity falls within the neuroglia at the centre of oedematous areas, but this change is a secondary event and may well be due to partial ischaemia caused by the pressure of oedema fluid on vessels.
No convincing changes in cellular dehydrogenase activity are seen either in the early stages of tininduced oedema or at the edges of older lesions.

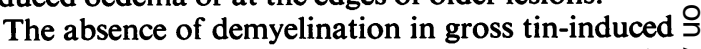
myelin oedema deserves particular comment. The $\rightarrow$ integrity of the myelin is clearly demonstrated by the normal staining of white matter with the OTAN $N$ method, including the absence of Marchi-positive breakdown products (cholesterol esters), and by the 0 absence of activated lipid-laden microglia (gitter $\omega$ cells). Magee et al. (1957) also indicated that there? 
was no demyelination in this condition. In spite of the severe distortion and swelling of white matter in triethyl-tin encephalopathy, it is concluded that myelin does not undergo either physical disintegration or chemical degradation.

RELATION OF OEDEMA TO DEMYELINATION In multiple sclerosis and experimental cyanide encephalopathy, the oligodendroglia proliferate, hypertrophy and undergo enzymic activation (Ibrahim and Adams, 1963, 1965: Ibrahim et al., 1963; Adams, Ibrahim, and Leibowitz, 1965; see also Friede, 1961; Friede and Knoller, 1964; van Houten and Friede, 1961). However, these changes were not observed either in the slight oedema induced by injection of distilled water and vasopressin or in the severe myelin oedema caused by triethyl-tin intoxication. Moreover, no evidence of myelin breakdown nor of gitter cell formation was found in either form of cerebral oedema. Likewise, no true demyelinating lesion, apart from non-specific necrosis, was observed in the cerebral oedema that accompanies immunological vascular damage (Leibowitz et al., 1961). It is concluded that the transudative types of cerebral oedema that were studied here neither cause oligodendroglial activation nor do they initiate the demyelinating process. The absence of demyelination in tin intoxication is particularly strong evidence against a pathogenic role of oedema in the demyelinating process. Such oedema is localized within or around the myelin yet it appears to be quite ineffective in promoting either physical disintegration or chemical degradation of myelin.

\section{SUMMARY}

No significant morphological or histoenzymic changes were observed in the oligodendroglia and microglia of rat brain in cases of mild water- and pitressin-induced cerebral 'oedema' or in the early stages of triethyl tin-induced myelin oedema. Equivocal swelling of the astrocytes was seen in pitressin 'oedema' and these cells were moderately swollen both at the centre and edges of long established areas of tin oedema, but in neither condition did these cells exhibit convincingly increased oxidative enzyme activity. The oligodendroglia at the centre of the older areas of tin oedema displayed both reduced oxidative enzyme activity and variable nuclear pallor. Even though triethyl-tin induces gross swelling and vacuolation of white matter, demyelination does not occur in either form of cerebral oedema. Likewise, lipid-laden microglia (gitter cells) were always absent. It is concluded that the mild and severe forms of cerebral oedema studied here could not be a causative factor in the demyelinating process. It is further concluded that these types of cerebral oedema do not provoke the oligodendroglial proliferation and enzymic activation that are seen in or around areas of demyelination in multiple sclerosis and experimental cyanide encephalopathy.

\section{REFERENCES}

Adams, C. W. M. (1959). A histochemical method for the simultaneous demonstration of normal and degenerating myelin. J. Path. Bact., 77, 648-650.

—, Davison, A. N., and Gregson, N. A. (1963). Enzyme inactivity of myelin: histochemical and biochemical evidence. J. Neurochem., 10, 383-395.

—_, Ibrahim, M. Z. M., and Leibowitz, S. (1965). Demyelination. In Neurohistochemistry, edited by C. W. M. Adams, ch. 11, Elsevier, Amsterdam. To be published.

Aldridge, W. N. (1958). The biochemistry of organotin compounds. Trialkyltins and oxidative phosphorylation. Biochem. J., 69, 367-376.

Aleu, F. P., Katzman, R., and Terry, R. D. (1963). Fine structure and electrolyte analyses of cerebral edema induced by alkyl tin intoxication. J. Neuropath. exp. Neurol., 22, 403-413.

Barlow, C. F. (1956). A study of abnormal blood-brain permeability in experimental allergic encephalomyelitis. Ibid., 15, 196-206.

Burstone, M. A. (1961). Modifications of histochemical techniques for the demonstration of cytochrome oxidase. J. Histochem. Cytochem., 9, 59-65.

Diezel, P. B. (1957). Die Stoffwechselstörungen der Sphingolipoide, p. 38. Springer, Berlin.

Friede, R. L. (1961). Enzyme histochemical studies in multiple sclerosis. Arch. Neurol. (Chic.), 5, 433-443.

(1964). The enzymatic response of astrocytes to various ions in vitro. J. Cell Biol., 20, 5-15.

, and Knoller, M. (1964). Quantitative enzyme profiles of plaques of multiple sclerosis. Experientia (Basel), 20, 130-132.

Gerschenfeld, H. M., Wald, F., Zadunaisky, J. A., and De Robertis, E. D. P. (1959). Function of astroglia in the water-ion metabolism of the central nervous system. An electron miscroscope study. Neurology (Minneap.), 9, 412-426.

Greenfield, J. G. (1939). The histology of cerebral oedema associated with intracranial tumours (with special reference to changes in the nerve fibres of the centrum ovale). Brain, 62, 129-152.

Hills, C. P., and Spector, R. G. (1963). Anoxia and cerebral water content in the adult rat. Nature (Lond.), 199, 393.

Ibrahim, M. Z. M., and Adams, C. W. M. (1963). The relationship between enzyme activity and neuroglia in plaques of multiple sclerosis. J. Neurol. Neurosurg. Psychiat., 26, 101-110.

- - (1965). The relationship between enzyme activity and neuroglia in early plaques of multiple sclerosis. J. Path. Bact., in the press.

—, Briscoe, P. B. Jr., Bayliss, O. B., and Adams, C. W. M. (1963). The relationship between enzyme activity and neuroglia in the prodromal and demyelinating stages of cyanide encephalopathy in the rat. J. Neurol. Neurosurg. Psychiat., 26, 479-486.

Johnson, A. C., McNabb, A. R., and Rossiter, R. J. (1950). Chemistry of Wallerian degeneration. A review of recent studies. Arch. Neurol. Psychiat. (Chic.), 64, 105-121.

Kalsbeck, J. E., and Cumings, J. N. (1963). Experimental edema in the rat and cat brain. J. Neuropath. exp. Neurol., 22, 237-247.

Klatzo, I., Piraux, A., and Laskowski, E. J. (1958). The relationship between edema, blood-brain-barrier and tissue elements in a local brain injury. Ibid., 17, 548-564.

Leibowitz, S., Morgan, R. S., Berkinshaw-Smith, E. M. I., and Payling Wright, G. (1961). Cerebral vascular damage in guineapigs induced by various heterophile antisera injected by the Forssmann intracarotid technique. Brit. J. exp. Path., 42, $455-463$.

Luse, S. A. (1960). Histochemical implications of electron microscopy of the central nervous system. J. Histochem. Cytochem., 8, 398-411. 
Luse, S. A., and Harris, B. (1961). Brain ultrastructure in hydration and dehydration. Arch. Neurol. (Chic.), 4, 139-152.

Magee, P. N., Stoner, H. B., and Barnes, J. M. (1957). The experimental production of oedema in the central nervous system of the rat by triethyltin compounds. J. Path. Bact., 73, 107-124.

Rubinstein, L. J., Klatzo, I., and Miquel, J. (1962). Histochemical observations on oxidative enzyme activity of glial cells in a local brain injury. J. Neuropath. exp. Neurol., 21, 116-136.

Schiffer, D., and Vesco, C. (1963). Histochemical observations about the pattern of tetrazolium reduction, with different substrates, in glia cells of normal and pathological human nervous tissue. J. Histochem. Cytochem., 11, 335-341.
Torack, R. M. (1965). Electron Histochemistry. In Neurohistochemistry, edited by C. W. M. Adams, ch. 5. Elsevier, Amsterdam. To be published.

-, Terry, R. D., and Zimmerman, H. M. (1959). The fine structure of cerebral fluid accumulation: I. Swelling secondary to cold injury. Amer. J. Path., 35, 1135-1147.

(1960). The fine structure of cerebral fluid accumulation: II. Swelling produced by triethyl tin poisoning and its comparison with that in the human brain. Ibid., 36, 273-287.

Van Houten, W. H., and Friede, R. L. (1961). Histochemical studies of experimental demyelination produced with cyanide. Exp. Neurol., 4, 402-412. 